\title{
Intracanopy Lighting Influences Radiation Capture, Productivity, and Leaf Senescence in Cowpea Canopies
}

\author{
Jonathan M. Frantz, Robert J. Joly, and Cary A. Mitchell ${ }^{1}$ \\ Department of Horticulture and Landscape Architecture, Purdue University, West Lafayette, IN 47907-1165
} ADDITIONAL INDEX wORDS. Vigna unguiculata, controlled environments, fluorometry, light-use efficiency, mutual shading,
senescence, spectroradiometry

\begin{abstract}
Traditional overhead lighting of dense crop stands in controlled environments favors development of upper leaf layers to maximize interception of light incident at the top of the foliar canopy. The resultant mutual shading of lower leaves in the understory of the canopy can severely limit productivity and yield of planophile crops. Intracanopy lighting alleviated the effects of mutual shading in dense, vegetative stands of cowpea [Vigna unguiculata (L.) Walp ssp. unguiculata] growing in a controlled environment by sustaining irradiance within the understory throughout development of this edible-foliage crop. For an overhead lighting system, photosynthetic photon flux $(P P F)$ in the understory was reduced to $1 \%$ of its initial value by 35 days of growth. $P P F$ in an intracanopy-lighted stand remained within $30 \mu \mathrm{mol} \cdot \mathrm{m}^{-2} \cdot \mathrm{s}^{-1}$ of initial values throughout the 50-day cropping period. Spectral distribution of radiation within the intracanopy-lighted stand also remained relatively constant throughout canopy development. In the overhead-lighted stand, violet and blue radiation in the understory decreased as much as $60 \%$ from initial values. Stability of the radiation environment within the intracanopy-lighted stand delayed leaf senescence 27 days beyond when interior leaves of the overhead-lighted canopy began to turn yellow on day 16. The intracanopy-lighted stand produced twice as much edible biomass per unit electrical energy consumed by lamps as for the overhead-lighted system. The treatment differences were due to the continuous presence of understory irradiation when using intracanopy lighting but not when using overhead lighting, and they underscore the importance of the entire foliar canopy in realizing the full productivity potential of dense crop stands in controlled environments.
\end{abstract}

High planting densities are used to maximize the productivity of crop stands within space-limited growing areas, as in greenhouses or growth chambers (Frick et al., 1994; Ohler et al., 1996). However, optimizing planting density for the highest productivity per unit area often forces individual plants into situations of intense competition for light. The shade-adaptation syndrome is a natural consequence of such competition, whereby plants may grow taller in effort to outcompete neighboring plants for limited light resources (Schmitt, 1997; Smith and Whitelam, 1997; Williams, 1963). The ability of some plants within a stand to capture light more effectively than others modifies growth of the neighboring, shaded plants, forcing them to adapt to a lower light environment. Individual plants within a community that grow taller than their neighbors might improve their own productivity, but productivity of the overall canopy typically suffers (Regnier and Stoller, 1989; Sutton and Weaver, 1989).

Promoting stand uniformity, however, does not eliminate competition within the stand. Leaves in the upper canopy still shade those in the understory, a condition known as mutual shading or self-shading (Begon et al., 1996). As a result of withinstand competition, environmental gradients develop within a crop canopy over time that, in turn, affect crop productivity and yield. In an eggplant (Solanum melongena L.) crop that devel-

Received for publication 29 Dec. 1999. Accepted for publication 8 Aug. 2000. Journal paper no. 15962 of the Purdue University Agricultural Research Project. This research was funded in part by NASA grant NAGW-2329. The authors thank Stephanie Hendrix and Jennifer Reinholt for their help with data collection and hydroponic system maintenance. Mention of a trademark, proprietary product, or vendor does not constitute a guarantee or warranty of the product by the U.S. Dept. of Agr. and does not imply its approval to the exclusion of other products or vendors that also may be suitable. The cost of publishing this paper was defrayed in part by the payment of page charges. Under postal regulations, this paper therefore must be hereby marked advertisement solely to indicate this fact.

${ }^{1}$ Corresponding author; e-mail mitchell@ @ort.purdue.edu. oped a closed canopy, air temperature was $2{ }^{\circ} \mathrm{C}$ lower at the base of the stand than at its top (Kitaya et al., 1998). Carbon dioxide concentration within the closed eggplant stand decreased $10 \%$ below the ambient level measured just above the stand. Watervapor pressure (humidity) became 17\% higher than the ambient level.

Environmental gradients form gradually within a crop stand by cumulative, plant-to-plant interactions as the canopy closes and matures. Within a uniform stand of field-grown wheat (Triticum aestivum L.), for example, large differences in spectral energy distribution occurred at different canopy heights as the stand developed (Holmes and Smith, 1977). Successive leaf layers attenuated wavebands of overhead light selectively, changing the interior spectral energy distribution relative to that incident on the top of the canopy. If a given species cannot adapt to irradiance and/or spectral changes in the understory, leaf senescence will begin (Behera and Biswal, 1990; Rousseaux et al., 1996).

Premature leaf senescence typically is associated with high within-stand competition for light during intensive crop cultivation. Because modern-day cropping practices have improved yields dramatically over the last half-century, it is difficult to imagine that current cultivation practices may have worsened some aspects of crop productivity. However, yield has been improved up to $33 \%$ in various crops by enhancing light penetration into the canopy or by adding supplemental light within the understory (Black, 1980; Johnston et al., 1969; Karami and Weaver, 1972; Pendelton et al., 1968; Tibbitts et al., 1993). The theory behind each approach to reduce mutual shading has been to improve both the quality and quantity of irradiance reaching the understory and thereby reduce or eliminate within-stand competition. A larger portion of the total canopy can participate in net carbon assimilation. 
Using intracanopy lighting as an alternative to overhead lighting (Frantz et al., 1998; Frantz et al., 2000), we have counteracted the vegetative yield reductions associated with mutual shading of closed canopies. This lighting strategy supplies irradiance entirely from within the canopy by allowing plants to grow among horizontal fluorescent lamp arrays at different heights above the hydroponic container. Rather than merely supplementing existing overhead lighting sources, intracanopy lighting distributes radiation throughout the canopy and does not supply any radiation from above after canopy closure. Intracanopy lighting as a sole source of radiation allows potential understory productivity to be investigated independent of interactions arising from overhead lighting plus supplemental intracanopy lighting or by increasing penetration of overhead irradiance.

Cowpea (Vigna unguiculata ssp. unguiculata) was selected for study of intracanopy vs. overhead lighting effectiveness. It is a typical planophile species that exhibits mutual shading characteristics under overhead lighting (Ohler and Mitchell, 1995). Because it produces edible leaves as well as snap beans or dry beans (Maeda, 1985; Ohler et al., 1996), its yield as well as its overall productivity is very responsive to the effectiveness of its lighting environment. Because of its vigorous growth habit, its favorable harvest index, and its diversity of harvestible parts, cowpea is a promising candidate dry bean species for inclusion in future regenerative life-support systems to be deployed in space (Bubenheim et al., 1990). Previous studies validated that cowpea biomass grew more efficiently using intracanopy rather than overhead lighting (Frantz et al., 1998). Regardless of the method by which photosynthetically active radiation $(P A R)$ is provided to the understory, canopy structure and the environments therein can be expected to differ from those of canopies receiving only overhead lighting. These differences, in turn, should modify other characteristics of a crop stand such as convective airflow, tissue temperature within the stand, canopy gas-exchange characteristics, and stand productivity.

The objective of the present study was to characterize the inner-canopy environments of two cowpea stands that received either overhead fluorescent lighting or intracanopy fluorescent lighting over an entire crop-production period. We sought to understand a) why canopies that receive intracanopy lighting produce edible biomass more efficiently than do overhead-lighted stands, and b) what events trigger a reduction in productivity of overhead-lighted plant canopies. In this study, we measured radiation incident upon primary and trifoliate leaves at four locations within cowpea stands at regular intervals throughout crop development. We also measured tissue and air temperatures at the same locations to further characterize the canopy environment. In order to assess quantum efficiency of photosystem II (PS II) and possible adaptation to the changing light environment at those locations, single-leaf fluorescence measurements also were made (Larcher et al., 1990; Yang et al., 1996). We correlated all measured changes with leaf appearance, canopy productivity and structure, and biomass allocation.

\section{Materials and Methods}

Plant-growth Conditions. Cowpea (day-neutral breeding line 'IT87D-941-1') seeds were imbibed in petri dishes lined with three layers of Whatman No. 1 filter paper wetted with tap water. After $72 \mathrm{~h}$, individual germinated seedlings were wrapped and oriented root down in a 4 -cm-wide $\times 8$-cm-long polyester wick, which was then rolled and inserted within a 1-cm-diameter hole drilled through a $2.5 \times 3.75 \mathrm{~cm}$ (height $\times$ diameter) circular polyethylene plug. The seedling plug was then fitted into a hole in the polystyrene lid of a deep-batch, recirculating hydroponic system. The hydroponic system contained half-strength Hoagland's No. 1 nutrient solution with quarter-strength micronutrients (Hoagland and Arnon, 1950). Electrical conductivity (EC) and $\mathrm{pH}$ were measured and readjusted daily to values of $1200 \pm 150 \mu \mathrm{S} \cdot \mathrm{cm}^{-1}$ and $5.6 \pm 0.3 \mathrm{pH}$ units, respectively. The hydroponic root container was placed on the floor of a $0.61 \times 0.61$ $\times 1.22 \mathrm{~m}$ (length $\times$ width $\times$ height) compartment located within a walk-in growth chamber, with the solution reservoirs and pumps located beneath the growth containers. Each compartment contained 28 plants, providing a planting density of 75 plants $/ \mathrm{m}^{2}$. Cropping time was $50 \mathrm{~d}$ for cowpea stands, kept vegetative by removing flower buds as they appeared. The growth chamber was maintained at 18 -h days/6-h nights of $31 / 28{ }^{\circ} \mathrm{C}$ day/night temperatures. Warm night temperature stimulates vegetative growth and inhibits pod set.

Environmental measurements were replicated within a single canopy for each treatment. Additional canopies were grown to validate harvest data over time. All growth conditions were the same for each replication, although leaf area could not be measured in the second trial.

The overhead $(\mathrm{OH})$-lighted canopy used ten $15-\mathrm{W}$ cool-white fluorescent lamps (F15T8, General Electric, Fairfield, Conn.) arranged side-by-side and positioned horizontally at the top of a compartment (Fig. 1A). White-over-black polyvinyl film lined the compartment walls, the hydroponics container lid, and the area $2 \mathrm{~cm}$ above the lamp bank in order to scatter light uniformly within the compartment. Curtains constructed from the same reflective polyvinyl film completely enclosed the front of each compartment, eliminating loss of scattered light from the compartments.

The lighting system for the intracanopy (IC)-lighting treatment consisted of 11 of the same-type lamps used for the $\mathrm{OH}$ treatment. These lamps were arranged at four levels within the compartment. The lowest level consisted of two horizontal, parallel lamps, separated by $13 \mathrm{~cm}$ and positioned $16 \mathrm{~cm}$ above the hydroponics container lid, and three subsequent levels of three parallel, horizontal lamps separated by $5 \mathrm{~cm}$ and positioned 31,60 , and $80 \mathrm{~cm}$ above the growing surface (Fig. 1B). Each successive lamp tier was arranged perpendicular to the nextlower tier. Every lamp was surrounded by a 1-mm-thick mylar sleeve with a 1-cm-wide air space maintained between the lamp and film by a polystyrene spacer near the ends of the lamps. The film and air space prevented tissue scorch if plant tissue contacted the lamps during growth. Plants were allowed to grow around and through each tier of lamps. As the growing canopy reached a given tier of horizontal lamps, the next higher tier was then energized. Because $P P F$ at any given point within a canopy was the result of a particular lighting treatment as well as stage of canopy development, $P P F$ could not be standardized between treatments as is typically done for $\mathrm{OH}$-lighted canopies. However, total electrical energy consumed to energize lamps (kW-h) during a cropping period was standardized to provide approximately equal $(<2 \%$ difference) light-energy-consumption totals, in spite of local differences in $P P F$ or slightly different numbers of lamps between treatments.

Canopy ENVIRONMENT CHARACTERIZation. Reference points were preselected at four locations within each compartment (Fig. $1 \mathrm{~A}$ and $\mathrm{B})$. The reference points were positioned above the 
growth container and between or below lamps or lamp banks. These locations were chosen to provide a range of reference heights within a canopy and to include both primary and trifoliate leaves in the characterization. Furthermore, previous experiments with cowpea under similar growth conditions indicated these locations would be occupied by leaves (Frantz et al., 1998). Two leaves in similar irradiance environments at or near each reference point were selected to obtain average values for this reference point. In the event that a leaf did not develop at a preselected point, the closest leaf that intersected the horizontal plane containing that point was chosen for measurement.

Spectral measurements were made daily with a portable spectroradiometer (model LI-1800; LI-COR, Lincoln, Nebr.) at each reference point in both canopies. The spectroradiometer was calibrated by the manufacturer immediately prior to the start of the experiment. A fiber-optic probe (LI-1800-10; LI-COR) with a remote, cosine-corrected radiation collector (LI-1800-11; LICOR) was attached to the spectroradiometer and fastened to an adjustable metal rod secured to a ring stand. Each day, the collector was inserted into both compartments through slits in the curtains and positioned at each preselected reference point for a spectral measurement. Before a leaf developed at those locations, the radiation collector was oriented toward the closest energized lamp, and the sensor on the end of the rod was leveled with a spirit level. If a leaf developed at a preselected point, the sensor was inserted into the canopy and the rod onto which the probe was attached was rotated to orient the sensor parallel to the adaxial surface of the leaf. This procedure allowed measurements to be made with minimal canopy disturbance and avoided sensor movement during recordings. Scans were performed in 2-nm increments from 300 to $1100 \mathrm{~nm}$ immediately above and directly below $(\approx 0.25 \mathrm{~cm})$ each target leaf to characterize both the irradiance incident upon and transmitted through that leaf. The same leaves were measured daily at each position throughout the 50-d experiment.

Each scan created a data file, which was analyzed separately for PPF (integral from 400 to $700 \mathrm{~nm}$ ), violet (400 to $426 \mathrm{~nm}$ ), blue (426 to $490 \mathrm{~nm}$ ), green (490 to $560 \mathrm{~nm}$ ), yellow (560 to 586 $\mathrm{nm}$ ), orange (586 to 640$)$, and red (640 to $700 \mathrm{~nm}$ ) portions of the $P P F$ spectrum (Nobel, 1991). Red to far-red (R:FR) ratios were obtained by comparing the quantum flux at $660 \mathrm{~nm}$ (red) to that at $730 \mathrm{~nm}$ (far red). To calculate how incident light of each waveband color from $400 \mathrm{~nm}$ to $700 \mathrm{~nm}$ changed at each reference point, day zero was used as a standard value (100\%) and subsequent days were compared to day zero. Each scan was used to estimate the ratio of phytochrome in the red-absorbing and farred-absorbing forms $\left(\mathrm{P}_{\mathrm{r}}\right.$ and $\mathrm{P}_{\mathrm{fr}}$, respectively). Calculations for photostationary states of phytochrome $(\phi)$ were made from each file according to the equation of Sager et al. (1988).

$$
\phi=\frac{\sum_{300}^{800} \mathrm{~N} \lambda \sigma \rho \lambda}{\sum_{300}^{800} \mathrm{~N} \lambda \sigma \rho \lambda+\sum_{300}^{800} \mathrm{~N} \lambda \sigma \phi \rho \lambda}
$$

where $\mathrm{N}=$ photon flux $\left(\mathrm{mol} \cdot \mathrm{m}^{-2} \cdot \mathrm{s}^{-1}, \sigma_{\mathrm{r}}=\right.$ photochemical crosssection of $\mathrm{P}_{\mathrm{r}}\left(\mathrm{m}^{2} \cdot \mathrm{mol}^{-1}\right), \sigma_{\mathrm{fr}}=$ photochemical cross-section of $\mathrm{P}_{\mathrm{fr}}$ $\left(\mathrm{m}^{2} \cdot \mathrm{mol}^{-1}\right)$.

Leaf absorption efficiency was estimated as a simplified Lambert-Beer's Law:

Absorption efficiency $=\left[\left(\mathrm{I}_{\mathrm{o}}-\mathrm{I}\right) /\left(\mathrm{I}_{\mathrm{o}}\right)\right] \times 100(\%) \quad$ [Eq. 2]

where $\mathrm{I}$ is $P P F$ transmitted through a leaf and $\mathrm{I}_{\mathrm{o}}$ is $P P F$ incident upon that leaf. Because only incident and transmitted light were measured, the efficiency value combines reflected light with radiation absorbed. Reflected light within the 400 to $700 \mathrm{~nm}$ waveband normally accounts for $\approx 5 \%$ of incident radiation (Lambers et al., 1998).

Fluorescence measurements were made daily for both leaves at each reference point while each remained attached to its respective petiole from leaf initiation to senescence, using a PP Systems model OS-500 pulse-modulated fluorometer (PP systems, Haverhill, Mass). Minimal fluorescence $\left(\mathrm{F}_{\mathrm{o}}\right)$ of dark-adapted leaves was measured with a weak $\left(<3 \mu \mathrm{mol} \cdot \mathrm{m}^{-2} \cdot \mathrm{s}^{-1}\right)$ solid-state light source (emission maximum of $655 \mathrm{~nm}$, no radiation beyond $700 \mathrm{~nm})$. Maximal fluorescence $\left(\mathrm{F}_{\mathrm{m}}\right)$ was measured with an intense saturation pulse $\left(10,000 \mu \mathrm{mol} \cdot \mathrm{m}^{-2} \cdot \mathrm{s}^{-1}\right.$, duration $\left.800 \mathrm{~ms}\right)$ of white light from a 35-W halogen lamp. A measure of the potential PS II efficiency was estimated by the ratio $F_{v} / F_{m}$ where $F_{v}=F_{m}-$ $F_{o}$ (Bjorkman and Demmig, 1987; Krause and Weis, 1984).

The same two leaves at each location were used for fluorescence measurements throughout canopy development to reduce leaf-to-leaf variability in $\mathrm{F}_{\mathrm{v}} / \mathrm{F}_{\mathrm{m}}$ (Massacci and Jones, 1990). Darkadaption clips were attached to fishing line and hung from lamps during dark adaptation and measurement to maintain the leaves' positions within the canopy and their distances from lamps. Maintaining leaf positions also reduced the amount of mechanical stress the target leaves experienced during the daily measurements. After measurements were taken, the clips were removed from the compartments to prevent their shading of other leaves.

Tissue temperatures and differences between tissue and ambient air temperatures were recorded with a hand-held infrared thermometer (Everest Interscience, Tustin, Calif). Measurements were made daily for each leaf from leaf emergence through senescence or until day 45 of the cropping cycle. The same two leaves at each canopy location were measured throughout the 50d cropping cycle.

Harvest AND Statistics. After $50 \mathrm{~d}$, biomass was separated

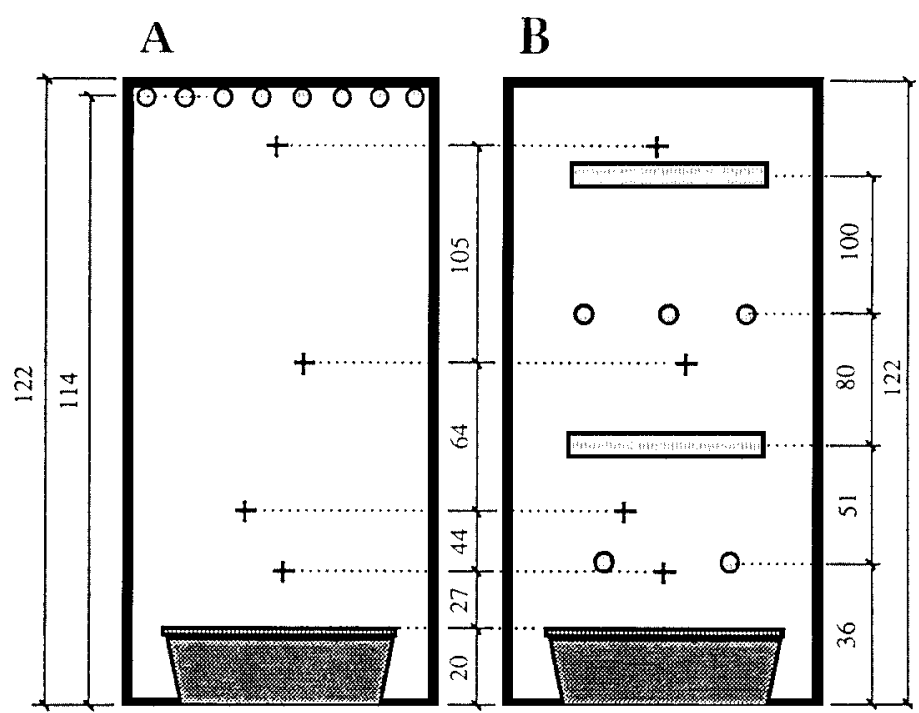

Fig. 1. Cross-sectional view of growth compartments. (A) Overhead-lighted compartment showing lamps (light-shaded circles: lamp axis perpendicular to the page) located at the top of the compartment (two lamps located behind and at right angles to the eight illustrated). (B) Intracanopy-lighted compartment showing lamps (five are illustrated as light-shaded circles; four were located behind the two depicted as light-shaded rectangles: lamp axis parallel to the page). (+) Measurement locations, which are at equivalent positions within each compartment. Hydroponic growth containers are depicted as dark-shaded trapezoids. All distances are in centimeters. Compartments were lined on all six surfaces with light-scattering, white, polyvinyl film. 


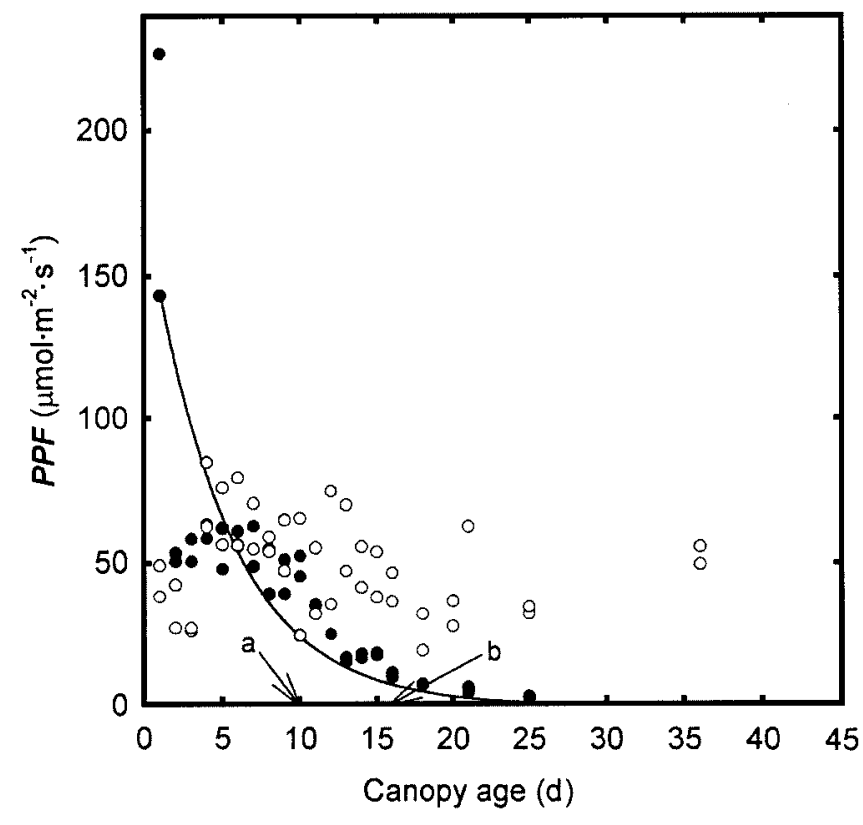

Fig. 2. Photosythetic photon flux $(P P F)$ incident upon the primary leaves over time for two canopies. Closed circles depict the overhead $(\mathrm{OH})$ treatment, whereas open circles depict the intracanopy (IC) treatment. PPF changes for the $\mathrm{OH}$ treatment are described by $\mathrm{f}(\mathrm{y})=176.1 \mathrm{e}^{-0.199 \mathrm{x}}, R^{2}=0.89$. There was no relationship over time for the changes in IC PPF. Arrow at (a) indicates when the next leaf layer formed above the primary leaves, and arrow at (b) indicates when senescence symptoms first appeared for the primary leaves of the $\mathrm{OH}$ lighted canopy.

into leaves, stems, and roots, dried in a forced-air oven at $70{ }^{\circ} \mathrm{C}$ for $72 \mathrm{~h}$, and weighed. Leaf area was measured immediately after harvest using a portable leaf area meter (LI-3000A; LI-COR). Harvest data are pooled totals of 28 plants in each canopy treatment. To verify that canopy yield differences were the result of the lighting treatments, a second study was performed. For the yield-replicate study, a $t$ test of unpaired samples was used to compare the means of each treatment.

Regression analysis was performed for each treatment using Sigma Plot (Version 4.0, Jandel Scientific, San Rafael, Calif) and tested by residual analysis with SAS procedures (SAS Inst. Inc., Cary, N.C.). In all instances, a single mathematical model was used to describe the measurements made over the 50-d cropping cycle. The criteria for selection of one model over another included the use of coefficient of multiple determination $\left(R^{2}\right)$, residual analysis to ensure random scattering of data points about the predicted model, and the feasibility of biological explanations for any higher-order terms.

\section{Results}

The two primary leaves of each plant became fully expanded $5 \mathrm{~d}$ after planting seedlings into the hydroponics systems of both lighting treatments. About every $5 \mathrm{~d}$ thereafter, an additional leaf layer formed above the existing one(s), regardless of the lighting treatment used. During the initial $2 \mathrm{~d}$ of treatment, $P P F$ incident upon the $\mathrm{OH}$-lighted primary leaves decreased from $180 \mu \mathrm{mol} \cdot \mathrm{m}^{-2} \cdot \mathrm{s}^{-1}$ to $\approx 50 \mu \mathrm{mol} \cdot \mathrm{m}^{-2} \cdot \mathrm{s}^{-1}$ (Fig. 2), which is well below the light-saturation point of $\approx 300 \mu \mathrm{mol} \cdot \mathrm{m}^{-2} \cdot \mathrm{s}^{-1}$ for young, lowlight-adapted cowpea leaves (Frantz et al., 1998). PPF continued to decrease for the $\mathrm{OH}$-lighted treatment, eventually reaching a value of $5 \mu \mathrm{mol} \cdot \mathrm{m}^{-2} \cdot \mathrm{s}^{-1}$ on day 35 . In the IC-lighted stand, $P P F$ varied from 28 to $>80 \mu \mathrm{mol} \cdot \mathrm{m}^{-2} \cdot \mathrm{s}^{-1}$ during the first $10 \mathrm{~d}$, indicating no relationship between $P P F$ and canopy development. Both young and old leaves of the IC treatment exhibited net, positive assimilation at $P P F$ levels as low as $20 \mu \mathrm{mol} \cdot \mathrm{m}^{-2} \cdot \mathrm{s}^{-1}$ (unpublished data of the authors). After the tenth day of growth, $P P F$ in the lower $25 \%$ of the IC-lighted stand varied but never fell below 20 $\mu \mathrm{mol} \cdot \mathrm{m}^{-2} \cdot \mathrm{s}^{-1}$ and averaged $44 \mu \mathrm{mol} \cdot \mathrm{m}^{-2} \cdot \mathrm{s}^{-1}\left( \pm 14 \mu \mathrm{mol} \cdot \mathrm{m}^{-2} \cdot \mathrm{s}^{-1}\right.$ $\mathrm{SD})$.

There were no significant changes in spectral energy distribution incident upon primary leaves during the initial 10-d period for either treatment (Fig. 3). However, after the first trifoliate leaf layer developed above the primary leaves, changes began to occur for most wavebands in both treatments. While violet, blue, and red decreased from initial values, concomitant relative increases occurred for the green and yellow wavebands. After the canopy closed above the primary leaf layer (day 10) for the $\mathrm{OH}$ lighted stand, the proportion of radiation in violet fell to $40 \%$ of initial values (Fig. 3A), while that in blue fell to $\approx 50 \%$ (Fig. 3B). Green and yellow increased to $130 \%$ (Fig. 3C) and to $125 \%$ (Fig. 3D) of initial values, respectively. Somewhat surprisingly, orange did not decrease more than $10 \%$ from initial values in either treatment (Fig. 3E), indicating equal amounts of absorbed and transmitted radiation in this waveband. The percentage of radiation in the red waveband gradually fell to $70 \%$ of initial values

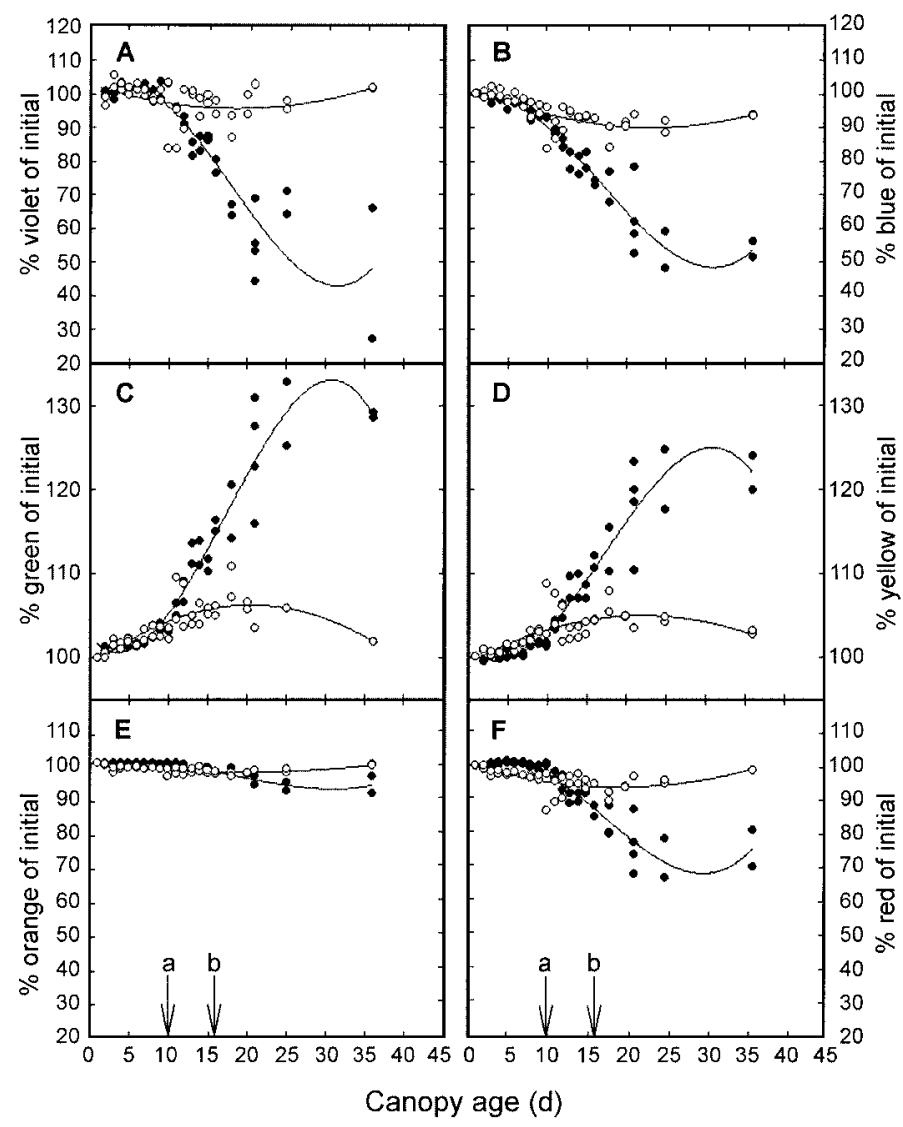

Fig. 3. Spectral energy distribution changes over time describing radiation incident upon the primary leaves for both treatments relative to initial radiation in that waveband. Closed circles depict the overhead $(\mathrm{OH})$ treatment and open circles depict the intracanopy (IC) treatment. Wavebands are (A) violet (400 to $426 \mathrm{~nm}),(\mathbf{B})$ blue $(426$ to $490 \mathrm{~nm}),(\mathbf{C})$ green $(490$ to $560 \mathrm{~nm}),(\mathbf{D})$ yellow $(560$ to $586 \mathrm{~nm}),(\mathbf{E})$ orange $(586$ to $640 \mathrm{~nm})$, and $(\mathbf{F})$ red $(640$ to $700 \mathrm{~nm})$ (Nobel, 1991). All OH spectral changes followed third-order regression models $\left(R^{2}=\right.$ 0.84 to 0.94$)$, whereas IC spectral changes followed second-order regression models $\left(R^{2}=0.19\right.$ to 0.66$)$. Points (a) and (b) are as in Fig. 2. 


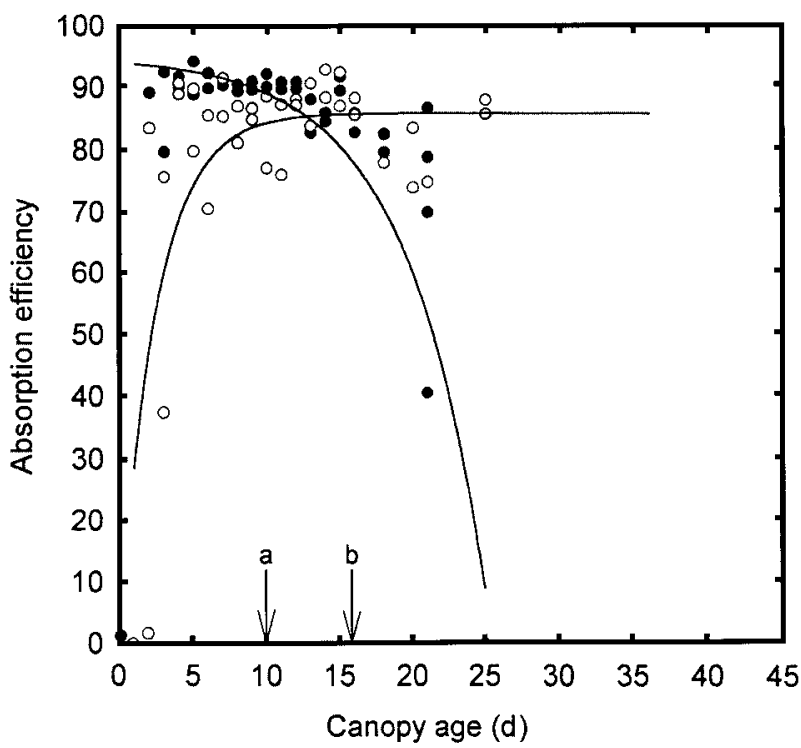

Fig. 4. Efficiency of radiation capture by the primary leaves of both lighting treatments. Closed circles depict the overhead $(\mathrm{OH})$ treatment, whereas open circles depict the intracanopy (IC) treatment. The light absorption profile for the $\mathrm{OH}$ treatment is described by a modified Michaelis-Menton equation $\mathrm{f}(\mathrm{y})=$ $92.66-[(5.84 \times \mathrm{x}) /(26.54-\mathrm{x})], R^{2}=0.91$, whereas that of the IC treatment is described by the Michaelis-Menton equation $\mathrm{f}(\mathrm{y})=(89.28 \times \mathrm{x}) /(1.69+\mathrm{x}), R^{2}=$ 0.40. Points (a) and (b) are as in Fig. 2.

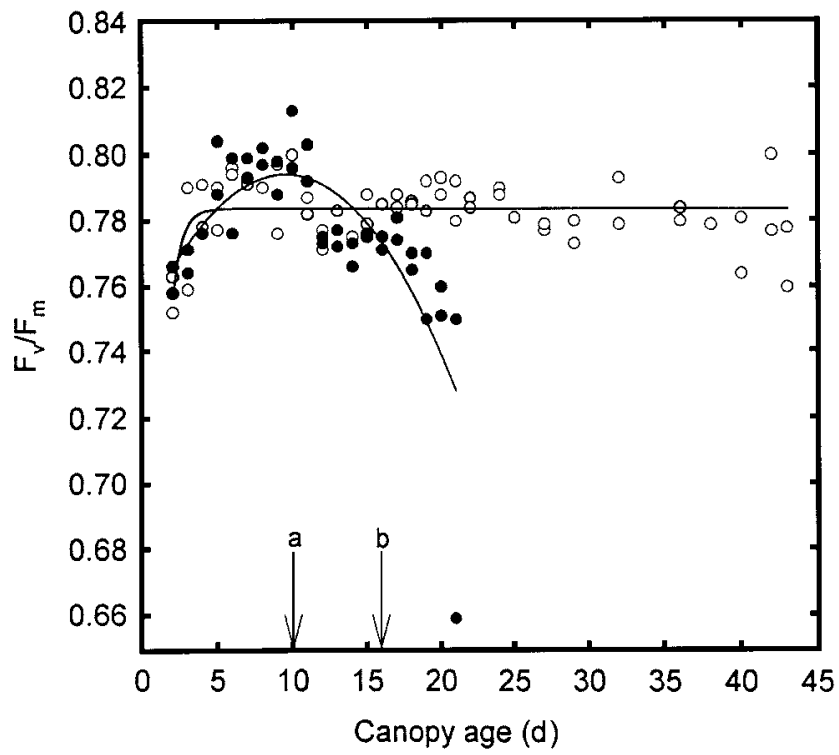

Fig. 5. $F_{v} / F_{m}$ profiles of primary leaves for both treatments throughout canopy development. Closed circles depict the overhead $(\mathrm{OH})$ treatment, whereas open circles depict the intracanopy (IC) treatment. The $\mathrm{F}_{\mathrm{v}} / \mathrm{F}_{\mathrm{m}}$ profile of the $\mathrm{OH}$ treatment is described by $\mathrm{f}(\mathrm{y})=0.75+0.0095 \mathrm{x}-0.0005 \mathrm{x}^{2}, R^{2}=0.59$, whereas the IC treatment is best described by the Michaelis-Menton equation $\mathrm{f}(\mathrm{y})=(0.79$ $* \mathrm{x}) /(0.036+\mathrm{x}), R^{2}=0.09$. Points $(\mathbf{a})$ and $(\mathbf{b})$ are as in Fig. 2.

after day 10 (Fig. 3F). During the entire 50-d cropping period, spectral-distribution changes for primary leaves in the $\mathrm{OH}$ lighted treatment were best described by a third-order regression model (Fig. 3). The percentage of radiation in each waveband incident upon the IC-lighted primary leaves changed at most only $10 \%$ from initial values. Throughout the 50-d cropping period, spectral-distribution changes followed a second-order regression model for the IC-lighted stand.

The PAR absorption efficiency of individual, $\mathrm{OH}$-lighted primary leaves remained at $90 \%$ by day 10 (Fig. 4). In the IClighted stand, absorption efficiency increased from about $40 \%$ to $\approx 80 \%$ during the initial 10 -d period. Light absorption began to decline after day 10 for the $\mathrm{OH}$ treatment, falling concomitant with the onset of lower leaf senescence on day 16. For the IC treatment, light-absorption efficiency remained relatively stable after day 10 at $80 \%$. Visual symptoms of senescence began to appear for the IC-lighted primary leaves on day 44 concomitant with a decrease in absorption efficiency.

The efficiency of PS II as estimated by $\mathrm{F}_{\mathrm{v}} / \mathrm{F}_{\mathrm{m}}$ increased from 0.76 to 0.80 during the first 10 days for both lighting treatments (Fig. 5). After this time interval, $\mathrm{F}_{\mathrm{v}} / \mathrm{F}_{\mathrm{m}}$ decreased for the $\mathrm{OH}-$ lighted stand and continued to decrease after the first visual signs of senescence appeared on day 16 . The $\mathrm{F}_{\mathrm{v}} / \mathrm{F}_{\mathrm{m}}$ of the IC treatment was relatively stable and remained at $98 \%$ of maximum fluorescence for 27 additional days after the onset of senescence by the $\mathrm{OH}$-lighted treatment.

The photostationary state of phytochrome $(\phi)$ in primary leaves remained near its maximum value of 0.85 through the onset of senescence and decreased $<2 \%$ during this time for the OH-lighted stand (Fig. 6). Beginning at day 18, however, $\phi$ decreased from 0.84 to 0.74 as the $\mathrm{OH}$ canopy continued to develop above the primary leaves. After senescence, no lateral branching or leaf initiation occurred in the lower, interior portions of the OH-lighted canopy. For the IC treatment, $\phi$ remained at $98 \%$ of its maximum value throughout the life of the primary leaves. Additional branching and leaf initiation occurred in the lower portion of the stand throughout the 50-d cropping cycle for the IC treatment.

The R:FR ratios decreased over time for both treatments from an initial value of 6.5 (Fig. 7). The $\mathrm{OH}$ treatment decreased from 6.5 and passed below 1.0 after day 16 , reaching a stable low of 0.3 after $25 \mathrm{~d}$. The IC treatment decreased initially from 6.5 to 2.0 , but increased again after day 25. The R:FR ratios never fell below 1.0 for the IC treatment.

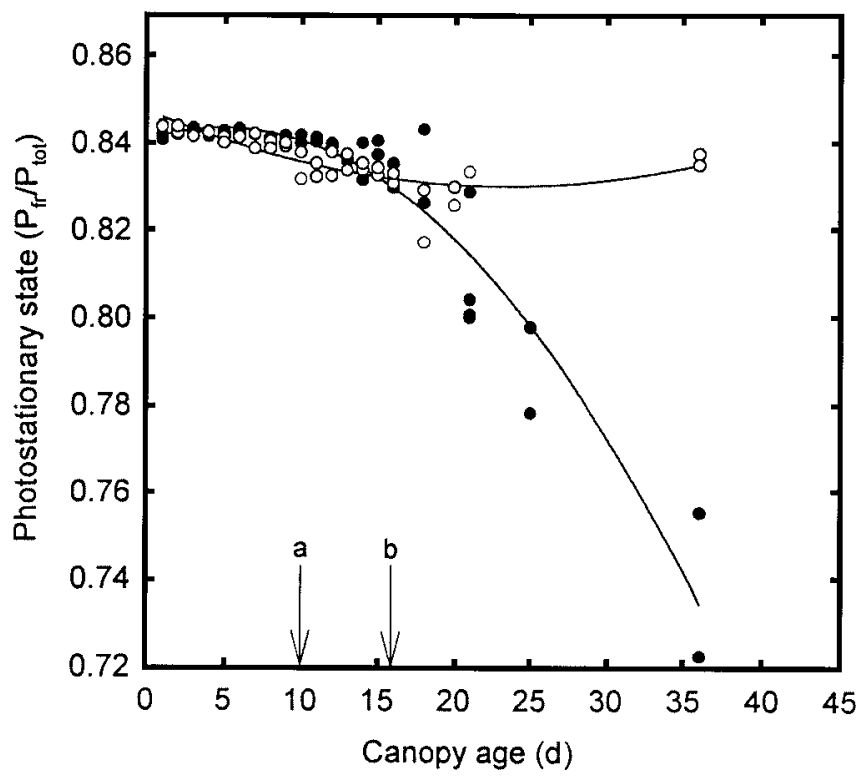

Fig. 6. Calculated $\left[\mathrm{P}_{\mathrm{fr}}\right]:\left[\mathrm{P}_{\mathrm{tot}}\right](\phi)$ for primary leaves over time for both lighting treatments. Closed circles depict the overhead $(\mathrm{OH})$ treatment and open circles depict the intracanopy (IC) treatment. The $\phi$ profile over time for the $\mathrm{OH}$ treatment is described by $\mathrm{f}(\mathrm{y})=0.84+0.0011 \mathrm{x}-0.00011 \mathrm{x}^{2}, R^{2}=0.92$, whereas that for the IC treatment is described by $\mathrm{f}(\mathrm{y})=0.85-0.0015 \mathrm{x}+0.0003 \mathrm{x}^{2}, R^{2}=$ 0.72. Points (a) and (b) are as in Fig. 2. 


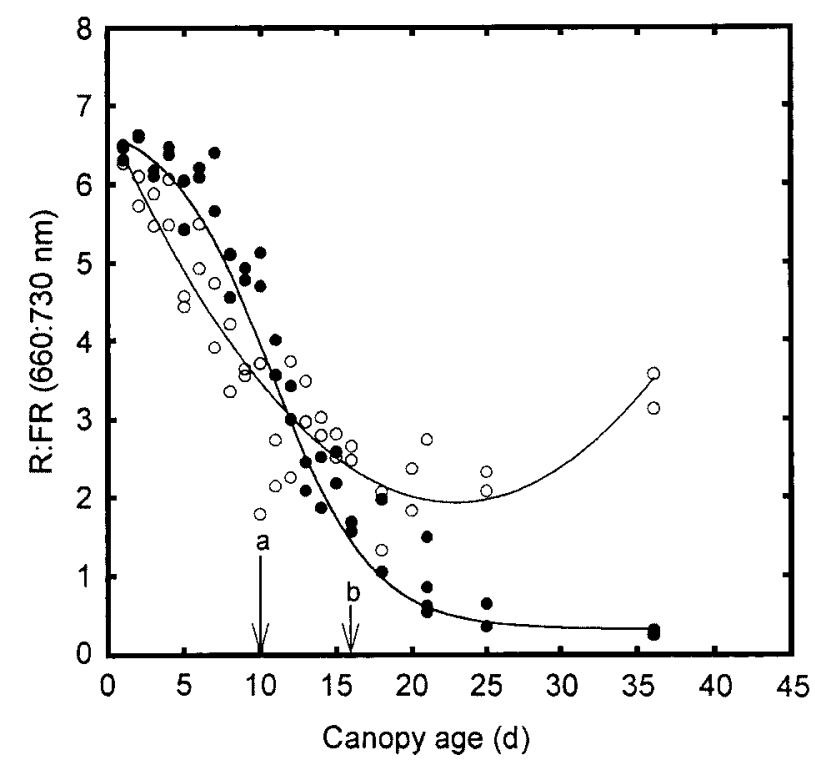

Fig. 7. R:FR ratio for primary leaves over time for both lighting treatments. Closed circles depict the overhead $(\mathrm{OH})$ treatment and open circles depict the intracanopy (IC) treatment. R:FR changes in the $\mathrm{OH}$ treatment were described by a modified sigmoidal curve $\mathrm{f}(\mathrm{y})=6.89-\left[6.56 /((1+\mathrm{e}-(\mathrm{x}-10.70) / 3.32)], R^{2}=0.95\right.$, while the IC treatment was described by a second-order model $\left(R^{2}=0.87\right)$. Points $(\mathbf{a})$ and (b) are as in Fig. 2.

No significant treatment differences occurred over time during canopy development for primary leaf temperature or the difference between leaf and air temperature for either lighting treatment. The tissue temperature of $\mathrm{OH}$-lighted leaves at any time, however, was between 0 and $2{ }^{\circ} \mathrm{C}$ below ambient air temperature. Intracanopy-lighted leaves always were warmer than the air temperature, remaining 1 to $2{ }^{\circ} \mathrm{C}$ above ambient throughout the life span of the primary leaves.

The radiation environment, tissue temperature, and $\mathrm{F}_{\mathrm{v}} / \mathrm{F}_{\mathrm{m}}$ of the primary leaves of the two lighting treatments were similar to those of the other three locations within each stand, with only minor differences between reference points. Generally, leaf senescence in the $\mathrm{OH}$-lighted canopy was delayed slightly from leaf initiation to senescence as the distance from a given leaf layer to the lamp bank decreased, but $\mathrm{OH}$-lighted leaves always senesced 3 weeks earlier than IC-lighted leaves. All parameters showed more variability the higher the measured leaf tissue was within the canopy.

Harvest Parameters. The IC-lighted cowpea stands consistently produced more leaf, stem, and root biomass than did $\mathrm{OH}-$ lighted stands for the equivalent amount of electrical input energy (Table 1). The IC-lighted canopy in the spectral study had a leafarea index (LAI) above 8 by day 50, while the LAI of the $\mathrm{OH}$ canopy was below 5 (Table 2). The IC-lighted stand produced 69\% more leaf dry matter, 50\% more stem dry weight, and 95\% more root weight than the $\mathrm{OH}$ canopy for equivalent energy input.

\section{Discussion}

In the IC-lighted stand, the radiation and temperature environments for a given leaf remained within a relatively narrow range throughout stand development, compared to leaves in the $\mathrm{OH}-$ lighted stand. Day-to-day environmental variations in the IClighted stand were attributable more to leaf distance from lamps changing by leaf reorientation than to canopy developmental stage (Frantz et al., 2000). An important effect of intracanopy lighting was to reduce mutual shading from newly formed upper leaf layers on existing lower leaves. While there was some absorption and reflection by the developing canopy, the radiation incident upon established leaves changed only slightly in spectral quality and did not change significantly in total $P P F$ over time.

The relative stability of the IC-lighting environment caused only very small changes in $\phi$ over time. Surprisingly, R:FR ratios decreased dramatically during the first 2 to 3 weeks, in spite of photoequilibria remaining stable. The discrepancy between $\phi$ and $R$ :FR changes is a result of $\phi$ being dependent on wavelengths other than red and far-red, especially blue. This dependence gives a more realistic estimate of photostationary states because phytochrome is affected by all visible wavebands to different extents. Furthermore, the lack of widespread agreement regarding what wavelengths or wavebands should be used in calculating R:FR ratios makes the calculation of $\phi$ more robust to errors associated with the use of different wavebands. The R:FR ratios never fell below those for sunlight $(\approx 1.0)$ in the IC-lighted stand, and even began to increase after day 30 , suggesting the occurrence of leaf reorientation and/or senescence within the canopy after day 30 . Consistent high values of $\phi$ were associated with branching and the formation of additional leaves in the understory.

Use of fluorescence was intended to quantify the onset of senescence beyond a qualitative, visual assessment, as well as to obtain an estimate of photosynthetic efficiency. The favorable IC light environment allowed PS II to remain at $98 \%$ of maximum efficiency for $\approx 42 \mathrm{~d}$ while leaves continued to absorb $66 \%$ to $85 \%$ of incident radiation. The IC leaves were never subjected to light environments that changed significantly over time and, as a result, did not begin to show symptoms of senescence until they were 44-d old. More leaf area photosynthesizing longer results in higher canopy photosynthetic rates (Stasiak et al., 1998) and improved crop productivity in the present study (Tables 1 and 2).

An additional effect of the IC-lighting treatment was that interior leaves were 1 to $2^{\circ} \mathrm{C}$ warmer than ambient air temperature. Tissue temperature plays an important role in leaf reorientation, a common leaf-adaptation strategy to more effectively

Table 1. Average harvest parameter totals for intracanopy (IC)-lighted and overhead $(\mathrm{OH})$-lighted cowpea stands.

\begin{tabular}{lrrc}
\hline \hline Harvest parameter & \multicolumn{1}{c}{$\mathrm{IC}$} & $\mathrm{OH}$ & $P^{\mathrm{z}}$ \\
\hline Leaf dry wt $\left(\mathrm{g} \cdot \mathrm{m}^{-2}\right)$ & 149.2 & 78.1 & $<0.0001$ \\
Stem dry wt $\left(\mathrm{g} \cdot \mathrm{m}^{-2}\right)$ & 124.9 & 104.8 & $<0.001$ \\
Root dry wt $\left(\mathrm{g} \cdot \mathrm{m}^{-2}\right)$ & 20.7 & 14.5 & $<0.02$ \\
Energy use $\left(\mathrm{kW}-\mathrm{h} / \mathrm{m}^{2}\right)$ & 341.1 & 339.0 & NS
\end{tabular}

$\overline{{ }^{\mathrm{z}} \text { Each treatment was replicated three times }(\mathrm{n}=3) . P \text { obtained from } t \text { test }}$ of means between the two treatments

NsNonsignificant.

Table 2. Harvest parameter totals for an intracanopy (IC)-lighted stand and an overhead $(\mathrm{OH})$-lighted cowpea stand in which spectral analyses were performed daily for both stands throughout the 50-day cropproduction cycle.

\begin{tabular}{lcc}
\hline \hline Harvest parameter & IC & OH \\
\hline Leaf area $\left(\mathrm{m}^{2}\right)$ & 3.10 & 1.82 \\
Leaf area index $\left(\mathrm{m}^{2}\right.$ leaf $/ \mathrm{m}^{2}$ growing area) & 8.34 & 4.90 \\
Leaf dry wt $\left(\mathrm{g} \cdot \mathrm{m}^{-2}\right)$ & 166.5 & 98.2 \\
Stem dry wt $\left(\mathrm{g} \cdot \mathrm{m}^{-2}\right)$ & 143.0 & 93.7 \\
Root dry wt $\left(\mathrm{g} \cdot \mathrm{m}^{-2}\right)$ & 17.4 & 8.9 \\
Energy use $\left(\mathrm{kW}-\mathrm{h} / \mathrm{m}^{2}\right)$ & 310.1 & 315.1 \\
\hline
\end{tabular}


intercept scattered or indirect radiation (Clearwater and Gould, 1995; Fu and Ehleringer, 1989; Stenberg, 1996). It is conceivable that the slightly warmer tissue temperatures favored leaf reorientation to better intercept available light and to remain photosynthetically active longer. Leaf reorientation within IC-lighted environments is an adaptation strategy to make the most efficient use of light from very different lamp orientations (Frantz et al., 2000), and is known to occur for legumes other than cowpea (Koller, 1986).

While the radiation environment in the IC-lighted stand was characterized by stability, that of the $\mathrm{OH}$-lighted treatment was marked by large environmental changes over time (Fig. 2). While the light itself did not change at a given location, the relatively constant $P P F$ between days 3 and 10 likely reflects early reorientation of primary leaves to better intercept scattered light before additional leaf layers formed above the primary leaves. Therefore, the amount of light intercepted by a leaf at a given location can change as the leaves reorient from 10 to $25^{\circ}$ off horizontal (observed values). Total PPF incident upon primary leaves in the OH-lighted canopy had declined as much as $94 \%$ from initial values when those leaves began to senesce. Not only did incident $P P F$ decrease with time, but the quality of that radiation changed as well. If irradiance was provided only from above the stand, upper leaves selectively attenuated red, blue, and violet wavebands as radiation filtered downward through successive leaf layers into the understory (Fig. 3). The greater scattering of shorter wavelengths as light filters through the canopy probably accounts for the larger decrease in violet relative to wavebands that generally are considered to be more important photosynthetically (i.e., red and blue). An altered spectral distribution is known to impact photosynthetic efficiency (Geiger, 1994) and to signal changes in the growth and development of crop stands (Bugbee, 1994; Dougher and Bugbee, 1998). Preferential absorption of red light, for example, results in decreased R:FR ratios $(660: 730 \mathrm{~nm})$ of filtered irradiance within the canopy. In dense shade, as was eventually created in $\mathrm{OH}$-lighted stands, R:FR decreased from 6 to $<1$ in $\approx 3$ weeks. Such changes in R:FR ratios as well as decreases in the proportion of irradiance in the blue waveband lead to shifts in $\phi$ because far-red irradiance contributes a larger percentage of residual radiation and shifts the $\mathrm{P}_{\mathrm{r}} / \mathrm{P}_{\text {fr }}$ equilibrium toward the $\mathrm{P}_{\mathrm{r}}$ form of phytochrome. Some plant responses to lowered $\phi$ include reductions in tillering, branching, leaf development, and flowering for a wide range of species (Smith and Whitelam, 1997 and references therein). Late in stand development for the $\mathrm{OH}$-lighted canopy, there was no leaf, flower, or lateral branch initiation in the lower third of the cowpea canopy. Lack of photosynthetic surface and reproductive sinks in the understory (as well as lack of light) reduces stand photosynthetic rates and lowers canopy productivity (Tables 1 and 2; Ohler and Mitchell, 1995).

Single-leaf fluorescence measurements indicated peak photosynthetic efficiency coinciding with full leaf expansion. The fluorescence measurements also indicated an immediate decline in efficiency during successive leaf-layer formation above the measured leaf. Fluorescence values stabilized temporarily from days 10 to 15 , but subsequent decline suggests the environment changed more rapidly than leaf-adaptation capabilities.

The $\phi$ of primary leaves began to decrease substantially after day 18 in the $\mathrm{OH}$-lighted canopies, decreasing to $\approx 0.74$ on day 35 . Before that time, $\phi$ remained at $\approx 98 \%$ of its calculated maximum value of 0.85 for irradiation with fluorescent lamps. Decreasing $\phi$ has been reported to correlate with senescence of field-grown sunflower (Helianthus annuus L.) (Rousseaux et al., 1996) and fern (Nephrolepis exaltata Schott) (Behera and Biswal, 1990), but spring barley (Hordeum vulgare L.) had no response upon exposure to far-red light (Skinner and Simmons, 1993). In the present study, $\phi$ did not fall below 0.835 until day 18 in the $\mathrm{OH}$ lighted cowpea stand, which was well after both visual signs of senescence had appeared and $\mathrm{F}_{\mathrm{v}} / \mathrm{F}_{\mathrm{m}}$ had declined. Intracanopyirradiated leaves were just below the 0.835 level for $10 \mathrm{~d}$ but did not themselves senesce. Sunlight creates a $\phi$ of 0.71 (calculated from measured scans of sunlight), which suggests that $\phi$, and therefore phytochrome, did not initiate leaf senescence of cowpea leaves for the $\mathrm{OH}$-lighted treatment. The absence of a reduction in $\phi$ to below values measured in sunlight, coupled with the drop in fluorescence on day 5, when R:FR ratios and other spectral parameters had not changed substantially from initial values, suggests that a reduction in light quantity rather than quality was responsible for the onset of leaf senescence. While it is often convenient experimentally to use a single correlate such as R:FR ratio to quantify the extent of spectral changes within a canopy, reliance on a single parameter ignores the complex environmental interactions occurring within a canopy. The magnitude and timing of all environmental changes are important to document for any canopy, but are especially important when comparing different light environments with the overall goal of improving stand productivity.

Another environmental factor that may play a significant role in leaf adaptation to radiation changes is tissue temperature. All understory leaves of $\mathrm{OH}$-lighted stands were as much as $2{ }^{\circ} \mathrm{C}$ cooler than ambient air temperature. This may have been caused by shading of lower, interior leaves, by evaporative cooling of canopy air by upper, transpiring leaves, or by increased distance from the radiant energy emitted by lamps. If leaf reorientation is indeed an important adaptive strategy to more efficiently use indirect or scattered light, then it is possible that the cooler tissue temperatures of $\mathrm{OH}$-lighted leaves either prevented or delayed leaf reorientation toward scattered understory light. The efficiency with which radiation was absorbed by leaves began to decrease after day 10, when the canopy closed, indicating that interior leaves may not have been as effective orienting themselves to intercept available, scattered light as they had been before canopy closure. The net result of these environmental changes was that leaves of the $\mathrm{OH}$-lighted treatment senesced between 16 and $21 \mathrm{~d}$ after initiating treatment, a full 25 to $27 \mathrm{~d}$ before IC-lighted leaves senesced.

Leaves in IC-lighted cowpea stands are subjected to far less change over time than are those within $\mathrm{OH}$-lighted stands. IC leaves remained productive much longer, absorbed radiation more efficiently, and photosynthesized more than 3 weeks longer than those in OH-lighted stands (Frantz et al., 1998). With additional leaf area exposed to $P A R$, canopy photosynthetic rates and productivity of IC-lighted stands can be improved if light is increased. The environmental and resulting physiological changes that occurred for individual leaves receiving $\mathrm{OH}$ lighting underscores the importance of effective light distribution within a crop stand in order to approach full yield potential. The inner canopy represents an enormous and virtually untapped resource for yield improvement, especially when growing area is a primary limitation.

\section{Literature Cited}

Begon M., J.L. Harper, C.R. Townsend. 1996. Ecology. $3^{\text {rd }}$ ed. Blackwell Press, Cambridge, Mass. 
Behera Y.N. and R. Biswal. 1990. Leaf senescence in fern: Effect of duration, intensity, and quality of light. Environ. Expt. Bot. 30:181186.

Bjorkman O. and B. Demmig. 1987. Photon yield of $\mathrm{O}_{2}$ and chlorophyll fluorescence characteristics at $77 \mathrm{~K}$ among vascular plants of diverse origins. Planta 170:489-504.

Black L.L. 1980. "Aluminum" mulch, less virus disease, higher vegetable yields. La. Agr. 23:16-18.

Bubenheim, D.L., C.A. Mitchell, and S.S. Nielsen. 1990. Utility of cowpea foliage in a crop production system for space, p. 535-538. In: J. Janick and J.E. Simon (eds.). Advances in new crops. Timber Press, Portland, Ore.

Bugbee B.G. 1994. Effects of radiation quality, intensity, and duration on photosythesis and growth. Intl. Lighting in Controlled Environ. Wkshp. NASA-CP-95-3309:39-50.

Clearwater M.J. and K.S. Gould. 1995. Leaf orientation and light interception by juvenile Pseudomonas crassifolius (Cunn.) C. Koch in a partially shaded forest environment. Oecologica 104:363-371.

Dougher T.A.O. and B.G. Bugbee. 1998. Is blue light good or bad for plants? Life Support Biosphere Sci. 5:129-136.

Frantz J.M., C. Chun, R.J. Joly, and C.A. Mitchell. 1998. Intracanopy lighting of cowpea canopies in controlled environments. Life Support Biosphere Sci. 5:183-189.

Frantz J.M., R.J. Joly, and C.A. Mitchell. 2000. Improving productivity of cowpea using intracanopy lighting by changing canopy light environments. Life Support Biosphere Sci. (in press).

Frick J., S.S. Nielsen, and C.A. Mitchell. 1994. Yield and seed oil content response of dwarf, rapid-cycling Brassica to nitrogen treatments, planting density, and carbon dioxide enrichment. J. Amer. Soc. Hort. Sci. 119:1137-1143.

Fu Q.A. and J.R. Ehleringer. 1989. Heliotropic leaf movements in common beans controlled by air temperature. Plant Physiol. 91:11621167.

Geiger D.R. 1994. General lighting requirements for photosynthesis. Intl. Lighting in Controlled Environ.Wkshp. NASA-CP-95-3309:317.

Hoagland D.R. and D.I. Arnon. 1950. The water culture method for growing plants without soil. Univ. Calif Expt Sta Circ. 347.

Holmes M.G. and H. Smith. 1977. The function of phytochrome in the natural environment-II. The influence of vegetation canopies on the spectral energy distribution of natural daylight. Photochem. Photobiol. 25:539-545.

Johnston T.J., J.W. Pendelton, D.B. Peters, and D.R. Hicks. 1969. Influence of supplemental light on apparent photosynthesis, yield, and yield components of soybeans (Glycine max L.). Crop Sci. 9:577-581.

Karami E. and J.B. Weaver, Jr. 1972. Growth analysis of American upland cotton, Gossypium hirsutum L., with different leaf shapes and colors. Crop Sci. 12:317-320.

Kitaya Y., T. Shibuya, T. Kozai, and C. Kubota. 1998. Effects of light intensity and air velocity on air temperature, water vapor pressure, and $\mathrm{CO}_{2}$ concentration inside a plant canopy under artificial lighting condition. Life Support Biosphere Sci. 5:199-203.

Koller D. 1986. The control of leaf orientation by light. Photochem. Photobiol. 44:819-826.

Krause G.H. and E. Weis. 1984. Chlorophyll fluorescence as a tool in plant physiology. II. Interpretation of fluorescence signals. Photosyn. Res. 5:139-157.
Lambers H., F.S. Chapin, and T.L. Pons. 1998. Plant physiological ecology. $1^{\text {st }}$ ed. Springer-Verlag, New York.

Larcher W., J. Wagner, and A. Thammathaworn. 1990. Effects of superimposed temperature stress on in vivo chlorophyll fluorescence of Vigna unguiculata under saline stress. J. Plant Physiol. 136:92-102.

Maeda E.E. 1985. Effect of solar dehydration on amino acid pattern and available lysine content in four tropical leafy vegetables. Ecol. Food Nutr. 16:273-279.

Massacci, A. and H.G. Jones. 1990. Use of simultaneous analysis of gasexchange and chlorophyll fluorescence quenching for analysing the effects of water stress on photosynthesis in apple leaves. Trees 4:1-8.

Nobel P.S. 1991. Physiochemical and environmental plant physiology. $1^{\text {st }}$ ed. Academic Press, San Diego, Calif.

Ohler T.A. and C.A. Mitchell. 1995. Effects of carbon dioxide and plant density on cowpea canopy productivity for a bioregenerative life support system. Life Support Biosphere Sci. 2:3-9.

Ohler T.A., S.S. Nielsen, and C.A. Mitchell. 1996. Varying plant density and harvest time to optimize cowpea leaf yield and nutrient content. HortScience 31:193-197.

Pendelton J.W., G.E. Smith, S.R. Winter, and T.J. Johnston. 1968. Field investigations of the relationships of leaf angle in corn (Zea mays L.) to grain yield and apparent photosynthesis. Agron. J. 60:422-424.

Regnier E.E. and E.W. Stoller. 1989. The effects of soybean (Glycine max) interference on the canopy architecture of common cocklebur (Xanthium strumarium), jimsonweed (Datura stramonium), and velvetleaf (Abutilon theophrasti). Weed Sci. 37:187-195.

Rousseaux M.C., A.J. Hall, and R.A. Sanchez. 1996. Far-red enrichment and photosynthetically active radiation level influence senescence in field-grown sunflower. Physiol. Plant. 96:217-224.

Sager J.C., W.O. Smith, J.L. Edwards, and K.L. Cyr. 1988. Photosynthetic efficiency and phytochrome photoequilibria determination using spectral data. Trans. Amer. Soc. Agr. Eng. 31:1182-1889.

Schmitt J. 1997. Is photomorphogenic shade avoidance adaptive? Perspectives from population biology. Plant Cell Environ. 20:826-830.

Skinner R.H. and S.R. Simmons. 1993. Modulation of leaf elongation, tiller appearance, and tiller senescence in spring barley by far-red light. Plant Cell Environ. 16:555-562.

Smith H. and G.C. Whitelam. 1997. The shade avoidance syndrome: multiple responses mediated by multiple phytochromes. Plant, Cell, Environ. 20:840-844.

Stasiak M.A., R. Côté, M. Dixon, and B. Grodzinski. 1998. Increasing plant productivity in closed environments with inner canopy illumination. Life Support Biosphere Sci. 5:175-181.

Stenberg P. 1996. Simulations of the effects of shoot structure and orientation on vertical gradients in intercepted light by conifer canopies. Tree Physiol. 16:99-108.

Sutton J.D. and D.B. Weaver. 1989. Intergenotypic competition between late-planted determinate and indeterminate soybean. Crop Sci. 29:15061510.

Tibbitts T., W.W. Cao, and R.M. Wheeler. 1993. Growth of potatoes for CELSS. Final Rpt. NASA Coop. Agreement NCC 2-301.

Williams W.A. 1963. Competition for light between annual species of Trifolium during the vegetative phase. Ecology 44:475-485.

Yang G.,D. Rhodes, and R.J. Joly. 1996. Effects of high temperature on membrane stability and chlorophyll fluorescence in glycinebetainedeficient and glycinebetaine-containing maize lines. Austral. J. Plant Physiol. 23:437-443. 